\title{
Role of Gibberellins in Chrysanthemum Growth under Far Red Light-deficient Greenhouse Environments
}

\author{
Sonja L. Maki, ${ }^{1}$ Sriyani Rajapakse, ${ }^{2}$ Robert E. Ballard, ${ }^{2}$ and Nihal C. Rajapakse $^{3}$ \\ Department of Horticulture, Clemson University, Clemson, SC 29634
}

\begin{abstract}
ADDITIONAL INDEX wORDS. spectral filters, R:FR ratio, plant growth regulators, photomorphogenesis, Dendranthema $\times$ grandiflora

Abstract. Plants grown in far red (FR) light deficient environments are typically shorter because of short internodes, resembling plants treated with GA biosynthesis inhibitors. The role of GAs in the reduction of stem elongation of 'Bright Golden Anne' chrysanthemum [Dendranthema $\times$ grandiflora (Ramat.) Kitam. (syn. Chrysanthemum $\times$ morifolium Ramat.)] grown in FR light deficient (-FR) environment was investigated by following the response of chrysanthemums grown in FR environment to exogenous application of $\mathbf{G A}_{1}, \mathbf{G A}_{19}$, or $\mathbf{G A}_{20}$, and the metabolism of $\mathbf{G A}_{12}$ and $\mathbf{G A}_{19}$ in $-\mathrm{FR}$ or $+\mathrm{FR}$ environment. FR light deficient environment resulted in $25 \%$ to $30 \%$ shorter plants than in +FR environment. Final height of $\mathrm{GA}_{1}$ - and $\mathrm{GA}_{20}$ - treated plants followed a quadratic pattern while that of $\mathrm{GA}_{19}$ treated plants followed a linear pattern as the dosage increased from 0 to $50 \mu \mathrm{g} / \mathrm{apex}$. The response to $\mathrm{GA}_{1}$ was the greatest followed by $\mathrm{GA}_{20}$ and $\mathrm{GA}_{19}$, regardless of the light environment. Application of $\mathrm{GA}_{1}(50 \mu \mathrm{g} / \mathrm{apex})$ increased final height by $65 \%$ compared with no GA $(0 \mu \mathrm{g} / \mathrm{apex})$ application under either +FR or -FR light environment, suggesting the response to $\mathrm{GA}_{1}$, which is the active form, remained

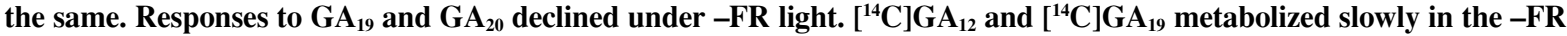
environment suggesting that the turnover of $\mathrm{GAs}$ may have caused in part the lower response to $\mathrm{GA}_{19}$. Although metabolism of $\mathrm{GA}_{1}$ under -FR environments was not investigated, observations with $\mathrm{GA}_{1}$ application experiments support that -FR environment may have enhanced inactivation of $\mathrm{GA}_{1}$. Chemical name used: gibberellic acid (GA).
\end{abstract}

Eliminating far red (FR) light from the greenhouse environment with liquid $\mathrm{CuSO}_{4}$ spectral filters has been shown to effectively reduce height in a wide range of plant species (Mortensen and Stromme, 1987; Rajapakse and Kelly, 1992). Although liquid $\mathrm{CuSO}_{4}$ filters have limited value to a commercial grower because of handling difficulties, development of photoselective plastic greenhouse covers with FR light removing properties could facilitate commercial applications of spectral filter technology. Plastic materials with FR light removing properties are not commercially available, but several plastic and pigment manufacturers are working together to develop such materials (Murakami et al., 1996; Oi et al., 1998; van Haeringen et al., 1998). Preliminary results indicate that plastic films and rigid plastic material with FR light absorbing dyes are effective in producing short, compact plants similar to those plants produced by chemical growth regulators or under liquid $\mathrm{CuSO}_{4}$ filters (Cerny et al., 1999; Li et al., 2000; Rajapakse et al., 1998).

Understanding the physiological mechanisms by which light quality (spectral composition) manipulates stem elongation could provide invaluable information for commercial development of photoselective greenhouse covers. Plants grown in a FR light deficient (-FR) environment are phenotypically similar to plants treated with chemical growth retardants that inhibit GA biosynthesis (Rajapakse and Kelly, 1992). In chrysanthemum [Dendranthema $\times$ grandiflora (syn.Chrysanthemum $\times$ morifolium], -FR environment induced reduction of stem elongation can be reversed by $\mathrm{GA}_{3}$ application or by exposure to end-of-the-day FR

Received for publication 2 July 2001. Accepted for publication 8 Apr. 2002. Technical contribution 4750 of the South Carolina Agricultural Experiment Station. The Ornamental Enhancement Research Program of the South Carolina Experimental Station and the Fred C. Gloeckner Foundation are gratefully acknowledged for financial support. We thank James Reick of the Department of Experimental Statistics at Clemson University for assistance with experimental design and data analysis.

${ }^{1}$ Current address: Department of Biology, Carleton College, Northfield, MN 55057.

${ }^{2}$ Department of Biological Sciences.

${ }^{3}$ Corresponding author; e-mail nrjpks@clemson.edu. light, indicating that both GAs and phytochromes are involved in mediating the response (Rajapakse and Kelly, 1991; Rajapakse et al., 1993).

The role of GAs in the inhibition of hypocotyl growth of deetiolating seedlings (dark grown seedlings exposed to light) has been investigated for decades. Two main theories have been proposed to explain the inhibition: exposure to light 1) alters active GA levels, resulting in inhibition of stem elongation and 2) reduces sensitivity of seedlings to active GAs. Evidence exists to support both of these theories. Campell and Bonner (1986) reported that conversion of $\mathrm{GA}_{20}$ to $\mathrm{GA}_{1}$ in pea (Pisum sativum $\mathrm{L}$.) occurred readily in dark-grown plants but that this conversion was blocked by R light. Martinez-Garcia and Garcia-Martinez (1992) reported that FR light increased stem elongation rate of cowpea [Vigna unguiculata (L.) Walp. ssp. unguiculata] seedlings that was related to increased levels of $\mathrm{GA}_{1}$. Toyomasu et al. (1992) reported that dark-grown lettuce (Lactuca sativa L.) seedlings contained higher levels of $\mathrm{GA}_{1}$ than seedlings exposed to white light. In contrast, Reid and Ross (1988) and Reid et al. (1991) provided evidence to support that the stem elongation response to changes in light was mediated by a change in sensitivity to GAs. Weller et al. (1994) reported that dark-grown pea seedlings were about three times taller than light-grown seedlings, but there were no substantial differences in $\mathrm{GA}_{1}$ levels in the apical regions. Recently, O'Neill et al. (2000) suggested that control of stem elongation of pea seedlings by light involves an initial inhibition of elongation by a light-induced decrease in $\mathrm{GA}_{1}$ levels, with continued inhibition mediated by a light-induced reduction of sensitivity to endogenous active GAs.

This research investigated the role of GAs in stem elongation of chrysanthemum in -FR environments. Specific objectives were to 1) determine the response of chrysanthemums grown in -FR environment to exogenous application of $\mathrm{GA}_{1}, \mathrm{GA}_{19}$, or $\mathrm{GA}_{20}$, and 2) determine whether metabolism of $\mathrm{GA}_{12}$ and $\mathrm{GA}_{19}$ differs in $-F R$ and $+F R$ environments. Chrysanthemum was selected because of its known response to light quality and its endogenous GAs have been identified (Nishijima et al., 1997). 


\section{Materials and Methods}

Plant Material and Culture. Uniform rooted stem cuttings of 'Bright Golden Anne' chrysanthemum with three to four leaves (Yoder Brothers, Pendleton, S.C.) were planted in 600-mL plastic pots containing a commercial potting medium (Fafard Mix 3B, Fafard, Anderson, S.C.). Plants were allowed to establish for 1 week in a glasshouse before treatment implementation. Plants were fertilized three times a week at irrigation with $1 \mathrm{~g} \cdot \mathrm{L}^{-1}$ of a $20 \mathrm{~N}-4.4 \mathrm{P}-$ 16.7K water soluble fertilizer (Peters 20-10-20 Peat-Lite Special, Scotts-Sierra Horticultural Products Co., Marysville, Ohio) during the experiment.

LIGHT ENVIRONMENT. The $+\mathrm{FR}$ and $-\mathrm{FR}$ treatments were randomly assigned to six constructed chambers (each $1.2 \times 1.2 \times 1.2 \mathrm{~m}$; three $+\mathrm{FR}$ and three $-\mathrm{FR}$ ) inside a glass greenhouse. Top (roof) of the -FR chambers were covered with $8 \mathrm{~mm}$ thick polycarbonate panels filled with $4 \% \mathrm{CuSO}_{4} \cdot 5 \mathrm{H}_{2} \mathrm{O}(\mathrm{w} / \mathrm{v})$. Top of the +FR chambers were covered with water filled panels. In each chamber, two fans (one attached to the lower left corner and the other attached to the upper right corner of the opposite side) were oriented in the same direction for airflow and to prevent heat buildup. The chamber sidewalls were covered with polyethylene (black on the outside and white on the inside) to prevent the transmission of nonfiltered natural light into the chambers. Average daily maximum $\left(28 \pm 2{ }^{\circ} \mathrm{C}\right)$ and minimum $\left(19 \pm 1{ }^{\circ} \mathrm{C}\right)$ temperatures inside $-\mathrm{FR}$ and $+\mathrm{FR}$ chambers were not different during the experimental period.

Photosynthetic photon flux $(P P F)$ inside each chamber was measured at the beginning and at the end of the experiment (between 1200 and $1300 \mathrm{HR}$ ) with a LI-250 quantum meter fitted with a LI-190SA sensor (LI-COR, Inc., Lincoln, Nebr.). The PPF was adjusted to be equal inside all chambers by covering the control chambers with cheesecloth. Average midday $P P F$ inside chambers on a clear day was $700 \pm 112 \mu \mathrm{mol} \cdot \mathrm{m}^{-2} \cdot \mathrm{s}^{-1}$.

Spectral photon distribution was measured at the beginning and at the end of the experiment with a LI1800 spectroradiometer fitted with a LI-1800-10 remote cosine sensor (LI-COR). The photon flux distribution (350 to $1100 \mathrm{~nm}$ at 10 -nm intervals) under $\mathrm{CuSO}_{4}$ filters has been reported previously (Rajapakse and Kelly, 1992). The R/FR ratios ( $\mathrm{R}=$ 600 to $700 \mathrm{~nm}$; FR = 700 to $800 \mathrm{~nm}$ ) were $1.1 \mathrm{in}$ water and 3.1 in $\mathrm{CuSO}_{4}$ chambers. The phytochrome photoequilibrium $\left(\mathrm{P}_{\mathrm{fr}} / \mathrm{P}_{\text {total }}\right)$ estimates of transmitted light were 0.72 in water and 0.80 in $\mathrm{CuSO}_{4}$ chambers (estimated as described by Sager et al., 1988).

Plant Response to Selected CONCENTRATIONS OF $\mathbf{G A}_{\mathbf{1}}, \mathbf{G A}_{\mathbf{1 9}}$, AND GA $\mathbf{G A}_{\mathbf{2 0}}$. GAs $\left(\mathrm{GA}_{1}, \mathrm{GA}_{19}\right.$, and GA 20 , purchased from Lew Mander, Australian National University, Canberra, Australia) were dissolved in 95\% ethanol, then diluted with distilled water to $50 \%$ ethanol. A group of five plants in each chamber was treated with 0 (control), $0.5,5,25$, or $50 \mu \mathrm{g} / \mathrm{apex}$ of each GA solution in a $10 \mu \mathrm{L}$ micro-drop on day 0 , 7,14 , and 21. Two control treatments were used: one set of control plants was treated with $10 \mu \mathrm{L}$ of $50 \%$ ethanol and the other set with $10 \mu \mathrm{L}$ of distilled water. GAs were applied along the midrib of the first fully opened leaf below the apex (Tatineni et al., 2000). Treated plants were placed randomly within each chamber. Plant height was recorded weekly.

Metabolism of $\mathbf{G A}_{12}$ AND $_{\mathbf{G A}_{19}} \cdot\left[{ }^{14} \mathrm{C}\right] \mathrm{GA}_{12}$ and $\left[{ }^{14} \mathrm{C}\right] \mathrm{GA}_{19}(1.85 \times$ $10^{9} \mathrm{~Bq} / \mathrm{mmol}$ ) were purchased from Lew Mander. Chrysanthemum plants were grown in $+\mathrm{FR}$ and $-\mathrm{FR}$ chambers for 2 weeks before treating them with radiolabeled GAs. Expanding leaves of 24 plants in each chamber were treated with $6 \times 10^{6} \mathrm{~Bq}$ of $\left[{ }^{14} \mathrm{C}^{-} \mathrm{GA}_{12}\right.$ or $\left[{ }^{14} \mathrm{C}_{\mathrm{GA}} \mathrm{A}_{19}\right.$ in a $10-\mu \mathrm{L}$ drop of $95 \%$ ethanol perplant. Application was made along the midrib of the newly expanded leaf. Following a 24 , 48,72 , or $96 \mathrm{~h}$ incubation period for $\mathrm{GA}_{12}$ and a 48, 72, 96, or 120 $h$ incubation period for $\mathrm{GA}_{19}$, apices including the treated leaf were harvested around $1200 \mathrm{HR}$ (six plants per incubation period for each GA) directly into liquid nitrogen, ground to a powder, and extracted

Fig. 1. Weekly height of 'Bright Golden Anne' chrysanthemums grown in + FR and -FR light environments in response to $\mathrm{GA}_{1}, \mathrm{GA}_{19}$, or $\mathrm{GA}_{20}$ treatment. Except for $\mathrm{GA}_{19}$ treatment in $+\mathrm{FR}$ environment, heights of plants treated with 25 or $50 \mu \mathrm{g} /$ apex were not different. Therefore, the response for $25 \mu \mathrm{g} / \mathrm{apex}$ is not shown in the graphs. Vertical bars indicate SE $(n=15)$. If the vertical bars are not seen, SE was smaller than the symbol.

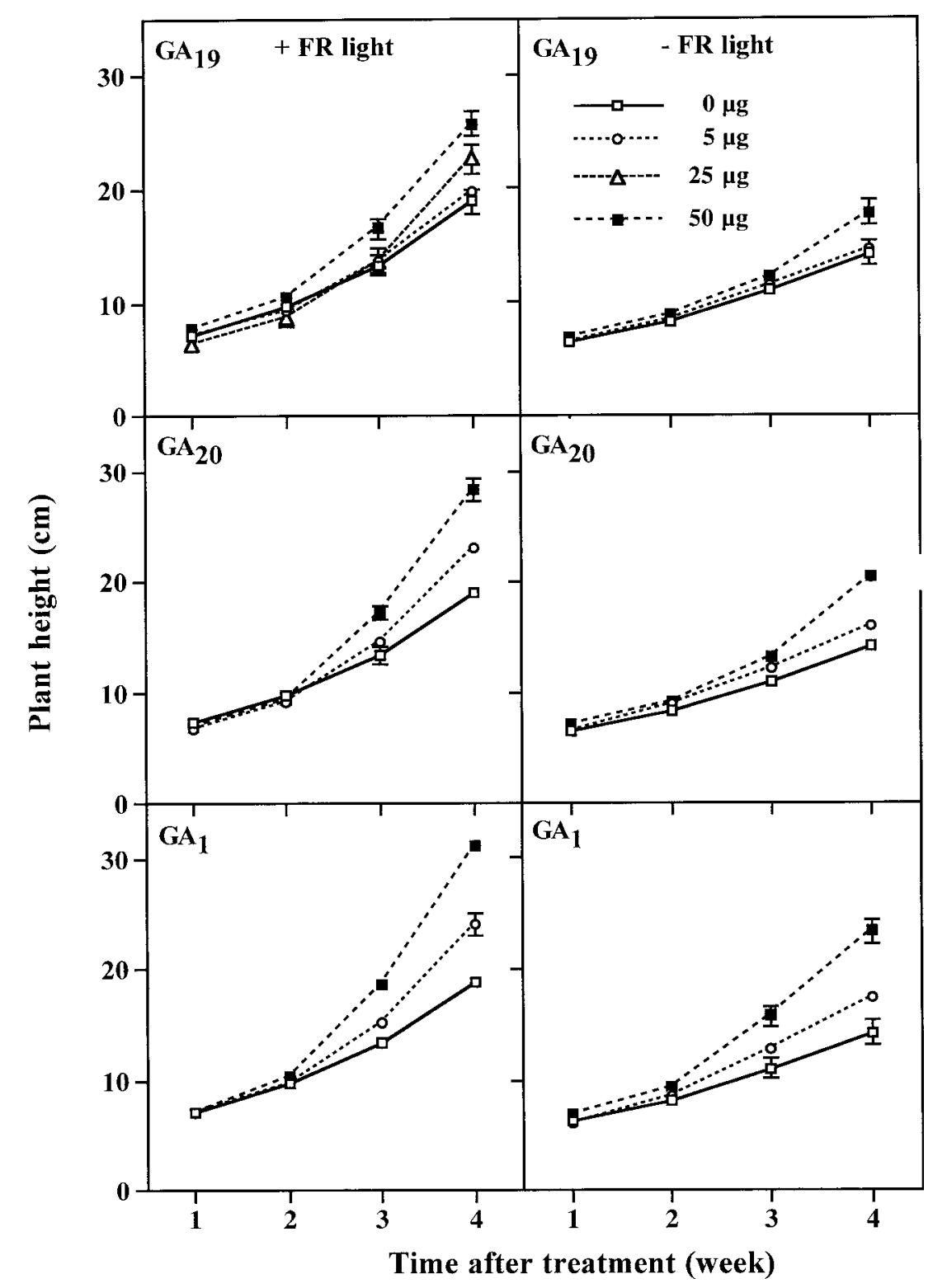



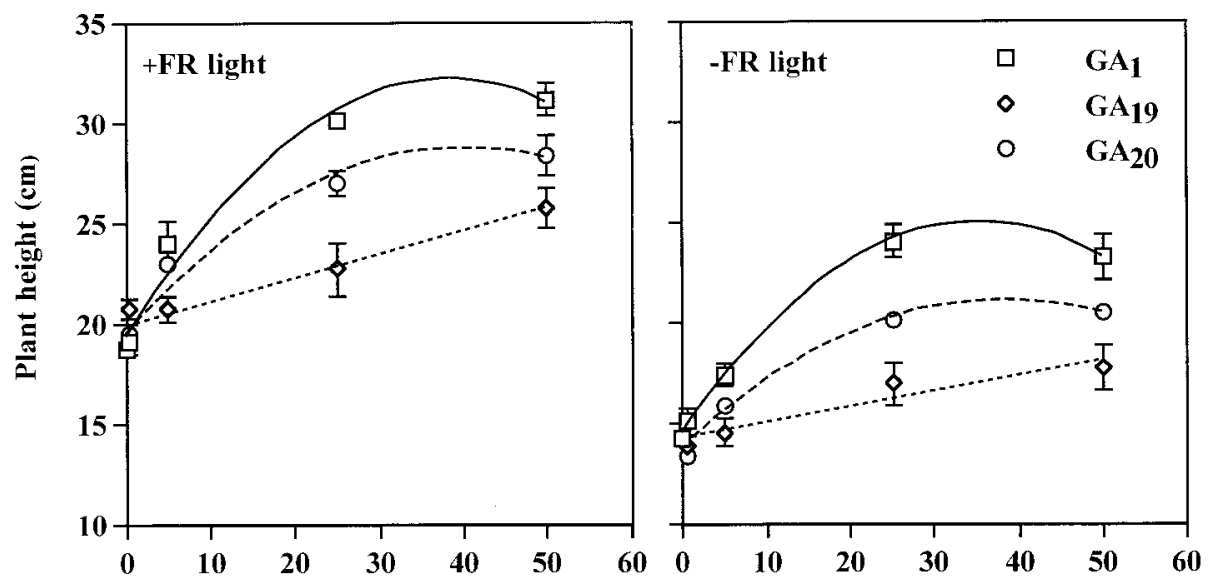

Dosage ( $\mu$ g per apex)

Fig. 2. Influence of exogenous $\mathrm{GA}_{1}, \mathrm{GA}_{19}$, or $\mathrm{GA}_{20}$ application and their dosage on final height of 'Bright Golden Anne' chrysanthemums grown with $(+\mathrm{FR})$ or without $(-F R)$ far red light. Vertical bars indicate SE $(n=15)$. If the vertical bars are not seen, the SE was smaller than the symbol. Lines were fitted to $y=b_{0}+b_{1} x$ or $\mathrm{b}_{0}+\mathrm{b}_{1} \mathrm{x}+\mathrm{b}_{2} \mathrm{x}^{2}$ where $\mathrm{y}$ is height $(\mathrm{Ht})$ and $\mathrm{x}$ is dosage. Predicted regression equations are: For $+\mathrm{FR} \mathrm{GA}_{1}, \mathrm{Ht}=19.6+0.66^{\mathrm{a}} \mathrm{x}-0.009^{\mathrm{A}} \mathrm{x}^{2}, r^{2}=0.98 ; \mathrm{GA}_{19}, \mathrm{Ht}=$ $19.6+0.12^{\mathrm{c}} \mathrm{X}, r^{2}=0.93$; and $\mathrm{GA}_{20}, \mathrm{Ht}=19.6+0.46^{\mathrm{b}} \mathrm{X}-0.006^{\mathrm{B}} \mathrm{X}^{2}, r^{2}=0.96$ : For $\mathrm{FR} \mathrm{GA}_{1}, \mathrm{Ht}=14.1+0.62^{\mathrm{a}} \mathrm{X}-0.009^{\mathrm{A}} \mathrm{x}^{2}, r^{2}=0.99 ; \mathrm{GA}_{19}, \mathrm{Ht}=14.1+0.15^{\mathrm{c}} \mathrm{x}, r^{2}=0.92$; and $\mathrm{GA}_{20}, \mathrm{Ht}=14.1+0.35^{\mathrm{b}} \mathrm{x}-0.005^{\mathrm{B}} \mathrm{x}^{2}, r^{2}=0.98$. Regression coefficients, $\mathrm{b}_{1}$ or $\mathrm{b}_{2}$, with same superscripted letter (lowercase and uppercase, respectively) were not significantly different at $P=0.05$. Predicted saturation dosages for $\mathrm{GA}_{1}$ and $\mathrm{GA}_{20}$ were 38.5 and $40.5 \mu \mathrm{g} / \mathrm{apex}$ for $+\mathrm{FR}$, and 35.5 and $39.3 \mu \mathrm{g} / \mathrm{apex}$ for $-\mathrm{FR}$ light treatments, respectively.

overnight in $50 \mathrm{~mL}$ of $80 \%$ methanol in distilled water. Following filtration through Whatman 3 filter paper, the residue was extracted twice with $15 \mathrm{~mL}$ of $100 \%$ methanol. The combined filtrates were reduced to the aqueous phase in vacuo at $35^{\circ} \mathrm{C}$ and purified as described by van Huizen et al. (1995) to obtain an acidic ethyl acetate fraction containing free GAs. Residue was first dissolved in $100 \mathrm{~mL}$ of methanol, followed by $900 \mathrm{~mL}$ of $0.01 \%$ trifluoroacetic acid (TFA). Radiolabeled products of the $\mathrm{GA}_{12}$ and $\mathrm{GA}_{19}$ were resolved by high-performance liquid chromatography (HPLC) on a reversed-phase Nova-Pak $5 \mathrm{~mm}$ Radial Pak column $(1.5 \times 8 \mathrm{~cm})$ (Waters Corp., Milford, Mass.), which performed the following gradient. The samples were eluted at a flow rate of $1.5 \mathrm{~mL} \cdot \mathrm{min}^{-1}$ using a programmed gradient of $0.01 \%$ TFA in $10 \%$ methanol solution (solvent A) and pure methanol (solvent B): $100 \%$ solvent A for $10 \mathrm{~min}, 30 \mathrm{~min}$ linear ramp to $70 \%$ solvent $\mathrm{B}, 15$ min linear ramp to $75 \%$ solvent $B$, and 2 min ramp to $100 \%$ solvent $B$. Fractions were collected (ISCO Foxy Jr., Lincoln, Nebr.) according to the retention times of radiolabeled standards, and detected by an on-line radioactivity monitor (INUS, Inc., Tampa, Fla.).

EXPERIMENTAL DESIGN, DATA COLLECTION, AND ANALYSIS. The experimental design was a randomized complete block design with a split-plot arrangement of the treatments. The light treatment was the whole plot factor. GAs and dosages were the subplot factors. A factorial treatment arrangement was used for the subplot factors. The experiment was repeated once to replicate. Plant height (distance from the growing medium to the apex) was measured weekly. Data were subjected to analysis of variance and linear and quadratic effects were tested using RSREG procedure of SAS (SAS Institute, Inc., Cary, N.C.). Since there were no significant differences between 50\% ethanol and distilled water controls in the application experiment, only the water control was used in data analysis.

\section{Results and Discussion}

Plant Response to GA $_{1}, \mathbf{G A}_{19}$, AND GA Go $_{20}$. Far red light deficient environment resulted in $\approx 25 \%$ to $30 \%$ shorter plants than in the $+\mathrm{FR}$ environment (Fig. 1). The reduction in stem elongation under -FR environment was evident within 2 weeks after treatment. Exogenous $\mathrm{GA}_{1}, \mathrm{GA}_{19}$, and $\mathrm{GA}_{20}$ promoted stem elongation but the magnitude of the increase varied with the type of GA, dosage, and the light environment. Plants treated with $\mathrm{GA}_{1}$, $\mathrm{GA}_{19}$, or $\mathrm{GA}_{20}$ at $0.5 \mu \mathrm{g} / \mathrm{apex}$ were not significantly taller than the water treated $(0 \mu \mathrm{g} / \mathrm{apex})$ plants under both light environments (datanot presented). $\mathrm{GA}_{1}$ and $\mathrm{GA}_{20}$ at $5 \mu \mathrm{g} / \mathrm{apex}$ increased height of plants grown in both light environments, but $\mathrm{GA}_{19}$ at $5 \mu \mathrm{g} / \mathrm{apex} \mathrm{did} \mathrm{not}$ increase height under either light environment. Application of $\mathrm{GA}_{1}, \mathrm{GA}_{20}$, or $\mathrm{GA}_{19}$ at $50 \mu \mathrm{g} /$ apex increased final height by $64 \%, 49 \%$, and $36 \%$, respectively, compared with no $\mathrm{GA}(0 \mu \mathrm{g} / \mathrm{apex})$ application under +FR light. Under-FR light, $\mathrm{GA}_{1}$, $\mathrm{GA}_{20}$, or $\mathrm{GA}_{19}$ at $50 \mu \mathrm{g} /$ apex increased final height by $65 \%, 44 \%$, and $25 \%$, respectively. Data suggest that the response to $\mathrm{GA}_{1}$, which is an active form, remained the same ( $64 \%$ vs. $65 \%$ ) between the two light environments, whereas responses to $\mathrm{GA}_{19}(36 \%$ vs. $25 \%)$ and $\mathrm{GA}_{20}(49 \%$ vs. $44 \%$ ) decreased under -FR light. This could have been due to reduced metabolism of $\mathrm{GA}_{19}$ and $\mathrm{GA}_{20}$ to the active form under-FR light. The height increase by $\mathrm{GA}_{19}$ was less than that of $\mathrm{GA}_{20}$ as it encompasses inhibition of metabolism one additional step $\left(\mathrm{GA}_{19}\right.$ to $\left.\mathrm{GA}_{20}\right)$ in the pathway compared to metabolism of $\mathrm{GA}_{20}$ to $\mathrm{GA}_{1}$. In a previous paper, Tatineni et al. (2000) reported that exogenous $\mathrm{GA}_{1}$ increased height of nonpaclobutrazol-treated and paclobutrazol-treated plants in a -FR light deficient environment created by photoselective greenhouse covers. This supports results herein that the-FR light environment did not reduce the response of plants to active GAs. Maas and van Hattum (1998) reported that differences in shoot elongation under various light and temperature conditions did not result from light quality or temperature mediated changes in plant response to $\mathrm{GA}_{1}$.

Final height of $\mathrm{GA}_{1}$ and $\mathrm{GA}_{20}$ treated plants followed a quadratic pattern while that of $\mathrm{GA}_{19}$ treated plants followed a linear pattern as the dosage per plant increased from 0 to $50 \mu \mathrm{g}$ (Fig. 2). Based on the regression analysis, the predicted saturation dosages for $\mathrm{GA}_{1}$ was 38.5 and $35.5 \mu \mathrm{g} / \mathrm{apex}$ under the + FR and -FR environments, respectively. If the reduction of stem elongation under-FR environment was mediated by reduced $\mathrm{GA}_{1}$ levels (due to reduced metabolism of $\mathrm{GA}_{19}$ or $\mathrm{GA}_{20}$ ), then the height of plants treated with a saturating level of $\mathrm{GA}_{1}(50 \mu \mathrm{g} / \mathrm{apex})$ in + and -FR environments should not be different. However, in the present investigation, final height of plants treated with $\mathrm{GA}_{1}$ at $50 \mu \mathrm{g} / \mathrm{apex}$ and grown under +FR light was about $33 \%$ greater $(31.2 \mathrm{~cm}$ vs. $23.4 \mathrm{~cm})$ than plants receiving the same dosage under -FR light (Fig. 1). O'Neill et al. (2000) suggested that light inhibition of stem elongation of pea seedlings involves an initial inhibition by a light-induced decrease in $\mathrm{GA}_{1}$ levels, with continued inhibition mediated by a light-induced reduction of sensitivity to endogenous active GAs. Recent research has shown that exposure to light enhances catabolism of active GAs to their inactive counterparts (Ait-Ali et al., 1999; Gil and GarciaMartinez, 2000). A possible explanation for our observation is that $\mathrm{GA}_{1}$ was catabolized faster under-FR light. It could also be possible that -FR light environment resulted in production of endogenous 
Table 1. Metabolism, as analyzed by HPLC-radiocounting, of $\left[{ }^{14} \mathrm{C}\right] \mathrm{GA}_{12}$ or $\left[{ }^{14} \mathrm{C}\right] \mathrm{GA}$, applied to 'Bright Golden Anne' chrysanthemum apices grown with $(+\mathrm{FR})$ or without $(-\mathrm{FR})$ far red light. Data are percentages of total radioactivity in the HPLC fraction corresponding to $\mathrm{GA}_{12}$, $\mathrm{GA}_{9} / \mathrm{GA}_{15}$, and $\mathrm{GA}_{19}$ or $\mathrm{GA}_{19}, \mathrm{GA}_{20}$, and $\mathrm{GA}_{1}$. Each value is the mean of 24 plants.

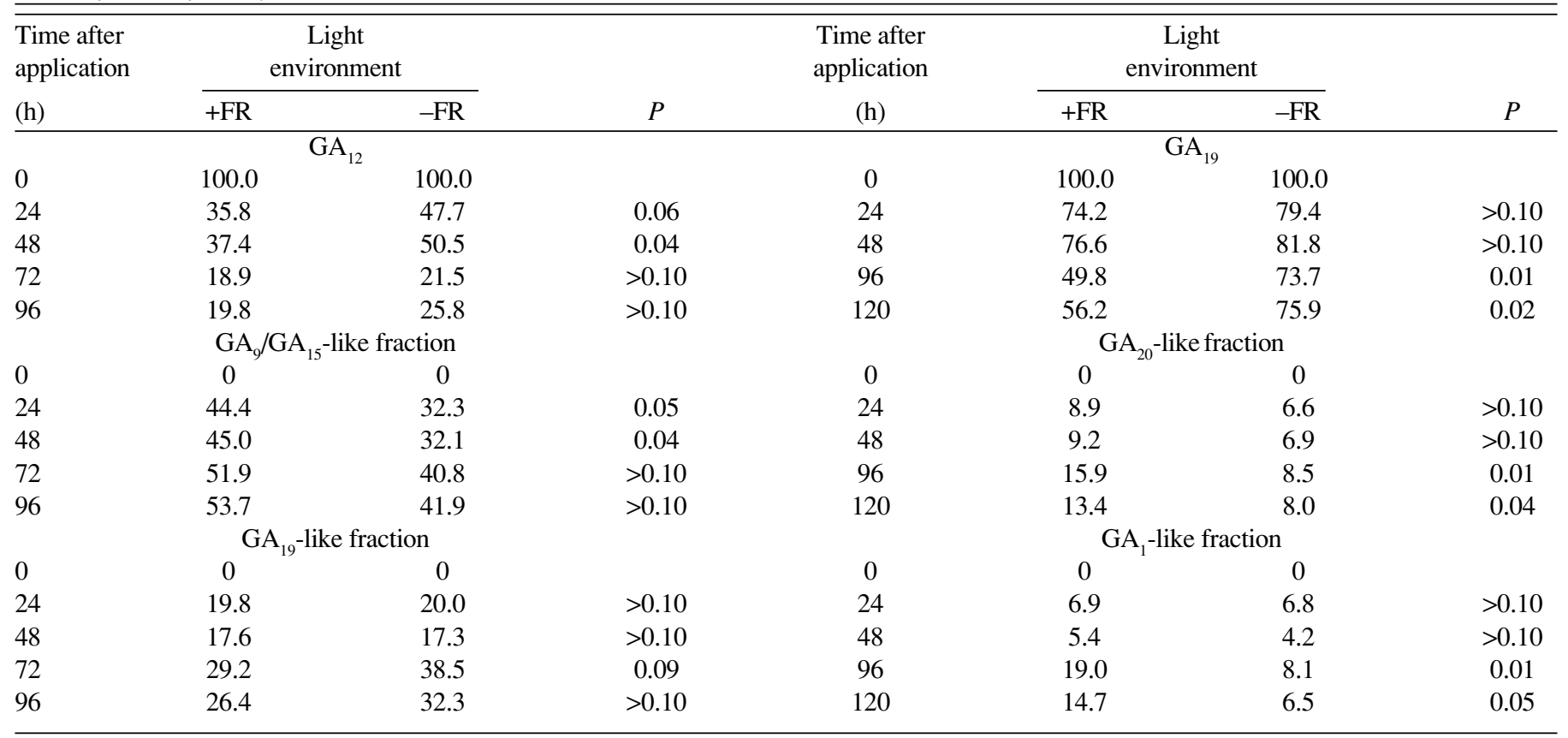

growth inhibitors. Noguchi and Hashimoto (1990) reported that exposure to $\mathrm{R}$ light produced unidentified endogenous growth inhibitors in pea plants that are controlled by phytochrome.

GibBerellin METabolisM. The data collected from HPLCradiocounting suggest that changes in light quality had an effect on metabolism of $\mathrm{GA}_{12}$ and $\mathrm{GA}_{19}$ (Table 1). [ ${ }^{14} \mathrm{C}_{\mathrm{GGA}}$ was metabolized to similar products in both environments. Radiolabeled peaks eluting at the retention times of $\mathrm{GA}_{19^{-}}, \mathrm{GA}_{15^{-}}$, and $\mathrm{GA}_{9}$-like substances were the major radiolabeled products present in the acidic ethyl acetate fraction. Radiolabeled products eluting in the $\mathrm{GA}_{9 / 15^{-}}$ like fraction were greater than the $\mathrm{GA}_{19}$-like fraction, indicating preference for the non-13-hydroxylation pathway for the applied $\mathrm{GA}_{12}$. The finding that $\left[{ }^{[14} \mathrm{C}\right] \mathrm{GA}_{12}$ was metabolized to $\mathrm{GA}_{9}$ and $\mathrm{GA}_{15-}$ like substances is not surprising. $\mathrm{GA}_{9}$ and trace levels of $\mathrm{GA}_{15}$, both non-13-hydroxylated GAs, have been identified in chrysanthemum (Nishijima et al., 1997), indicating that the non-13-hydroxylation pathway is also present in chrysanthemum. In vegetative pea plants, where both the 13-hydroxylation and non-13-hydroxylation pathways exist, GA 20-oxidase prefers nonhyroxylated substrates, even though 13-hydroxylated GAs predominate (Hedden, 1997). The percentage of $\left[{ }^{14} \mathrm{C}\right] \mathrm{GA}_{12}$ recovered during $48 \mathrm{~h}$ from plants grown in $+\mathrm{FR}$ environment was less than that recovered from plants grown in -FR environment, indicating that metabolism of $\left[{ }^{14} \mathrm{C}^{-} \mathrm{GA}_{12}\right.$ was slower in $-\mathrm{FR}$ environment. The percentage of $\mathrm{GA}_{9} / \mathrm{GA}_{15}$-like fraction recovered from $+\mathrm{FR}$ grown plants following $48 \mathrm{~h}$ incubation was greater than -FR grown plants but recovery of labeled $\mathrm{GA}_{19}$-like fraction was not different between light environments.

Metabolism of $\left[{ }^{14} \mathrm{C} \mathrm{GA}_{19}\right.$ was slower than that of $\left[{ }^{14} \mathrm{C}\right] \mathrm{GA}_{12}$ (Table 1). After $120 \mathrm{~h}$ of incubation, plants grown under the $+\mathrm{FR}$ environment had $\approx 56 \%$ recovery of $\left[{ }^{14} \mathrm{C}\right] \mathrm{GA}_{19}$ fraction compared to $75 \%$ recovery from those plants in -FR environment. Percentage recovery of $\mathrm{GA}_{20^{-}}$and $\mathrm{GA}_{1}$-like fractions increased as the incubation period increased. The percentage of labeled $\mathrm{GA}_{20}$ - and $\mathrm{GA}_{1}$-like fractions were greater in the $+\mathrm{FR}$ than $-\mathrm{FR}$ environment. These results suggest that metabolism of both $\left[{ }^{14} \mathrm{C}^{-} \mathrm{GA}_{12}\right.$ and $\left[{ }^{14} \mathrm{C} \mathrm{GA}_{19}\right.$ in -FR environment was reduced and that the reduced level of bioactive
GAs may have caused in part reduction of stem elongation underFR light. In the present application studies we found that final height of plants treated with $\mathrm{GA}_{19}$ at $50 \mu \mathrm{g} / \mathrm{apex}$ under $+\mathrm{FR}$ light was $45 \%$ greater $(25.8 \mathrm{~cm}$ vs. $17.8 \mathrm{~cm})$ than under -FR light. Final height of plants treated with $\mathrm{GA}_{20}$ at $50 \mu \mathrm{g} / \mathrm{apex}$ was $39 \%$ greater (28.4 vs. $20.5 \mathrm{~cm})$ than the corresponding plants grown under -FR light. Juntilla (1993) observed that while $\mathrm{GA}_{20}$ and $\mathrm{GA}_{1}$ counteracted the short day induced cessation of elongation growth in birch (Betula pubescens Ehrh.), $\mathrm{GA}_{19}$ was inactive. Beall et al. (1996) reported that turnover of $\mathrm{GA}_{19}$ in bean (Phaseolus vulgaris $\mathrm{L}$.) seedlings increased when FR light was added to the growing environment.

One limitation of the present study is that the inactive catabolic products of active GAs were not determined. $2 \beta$-hydroxylase is a key enzyme that catabolizes active $\mathrm{GAs}$, such as $\mathrm{GA}_{1}$ and $\mathrm{GA}_{4}$, to their inactive catabolites, $\mathrm{GA}_{8}$ and $\mathrm{GA}_{34}$, respectively. Recent work has shown that $\mathrm{GA}_{1}$ levels decreased rapidly and $\mathrm{GA}_{8}$ levels increased during de-etiolation of pea seedlings (Ait-Ali et al., 1999; Gil and Garcia-Martinez, 2000). However, the transcript levels coding for GA 20-oxidase and 3ß-hydroxylase enzymes (that catalyzes the conversion of $\mathrm{GA}_{19}$ to $\mathrm{GA}_{20}$ and $\mathrm{GA}_{20}$ to $\mathrm{GA}_{1}$, respectively) increased during de-etiolation indicating that reduced metabolism of $\mathrm{GA}_{19}$ or $\mathrm{GA}_{20}$ did not contribute to the decrease in $\mathrm{GA}_{1}$ levels. Martinez-Garcia et al. (2000) reported that end-of-day exposure to FR light increased $\mathrm{GA}_{1}$ levels in cowpea apices due to reduced inactivation of $\mathrm{GA}_{1}$. Although metabolism of $\mathrm{GA}_{1}$ under FR environments was not investigated, present observations with $\mathrm{GA}_{1}$ application experiments support that $-\mathrm{FR}$ environment may have enhanced inactivation of $\mathrm{GA}_{1}$. Exposure of plants to -DIF (higher night than day temperature) is another alternative that has been investigated widely to reduce stem elongation of greenhouse plants. Physiological basis of stem growth control by -DIF is not well understood but we believe that both light and temperature manipulation have similar mechanisms. Grindal et al. (1998) reported that exposure of pea plants to -DIF increased the ratio of $\mathrm{GA}_{8}: \mathrm{GA}_{1}$ suggesting that height reduction by -DIF was mediated through reduced $\mathrm{GA}_{1}$ levels via inactivation process. 
Data herein indicate that the response of chrysanthemum to exogenous $\mathrm{GA}_{1}$ was not reduced but the response to $\mathrm{GA}_{19}$ and $\mathrm{GA}_{20}$ was reduced under-FR light environment. The reduced response to $\mathrm{GA}_{19}$ and $\mathrm{GA}_{20}$ was probably mediated by reduction of GA metabolism. Although metabolism of $\mathrm{GA}_{1}$ under -FR environments was not investigated, observations with $\mathrm{GA}_{1}$ application experiments support that the -FR environment may have enhanced inactivation of $\mathrm{GA}_{1}$.

\section{Literature Cited}

Ait-Ali, T., S. Frances, J.L. Weller, J.B. Reid, R.E. Kendrick, and Y. Kamiya. 1999. Regulation of GA 20-oxidase and GA 3ß-hydroxylase transcript accumulation during phytochrome-mediated de-etiolation of pea seedlings. Plant Physiol. 121:783-791.

Beall, F.D., E.C. Yeung, and R.P. Pharis. 1996. Far red light stimulates internode elongation, cell division, cell elongation, and gibberellin levels in bean. Can. J. Bot. 74:743-752.

Campell, B.R. and B.A. Bonner. 1986. Evidence for phytochrome regulation of gibberellin $\mathrm{A}_{20} 3 \beta$-hydroxylation in shoots of dwarf (lele) Pisum sativum L. Plant Physiol. 82:909-915.

Cerny, T., N.C. Rajapakse, and R. Oi. 1999. Recent developments in photoselective greenhouse covers. Proc. Natl. Agr. Plastics Congr. 28:75-80.

Gil, J. and J.L. Garcia-Martinez. 2000. Light regulation of gibberellin $A_{1}$ content and expression of genes coding for GA 20-oxidase and GA $3 \beta$ hydroxylase in etiolated pea seedlings. Physiol. Plant. 108:223-229.

Grindal, G., A. Ernstsen, J.B. Reid, O. Junttila, B. Lindgård, and R. Moe. 1998. Endogenous gibberellin $A_{1}$ levels control thermoperiodic stem elongation in Pisum sativum. Physiol. Plant. 102:523-531.

Hedden, P. 1997. The oxidases of gibberellin biosynthesis: Their function and mechanism. Physiol. Plant. 101:709-719.

Junttila, O. 1993. Interaction of growth retardants, daylength, and gibberellins $\mathrm{A}_{19}, \mathrm{~A}_{20}$, and $\mathrm{A}_{1}$ on shoot elongation in birch and alder. J. Plant Growth Regulat. 12:123-127.

Li, S., R.E. Young, and N.C. Rajapakse. 2000. Growth response of chrysanthemum and bell pepper transplants to several photoselective plastic films. Scientia Hort. 84:215-225.

Maas, F.M. and J. van Hattum. 1998. Thermomorphogenic and photomorphogenic control of stem elongation in fuchsia is not mediated by changes in responsiveness to gibberellins J. Plant Growth Regulat. 17:39-45.

Martinez-Garcia, J.F. and J.L. Garcia-Martinez. 1992. Interaction of gibberellins and phytochrome in the control of cowpea epicotyl elongation. Physiol. Plant. 86:236-244.

Martinez-Garcia, J.F., C.M. Santes, and J.L. Garcia-Martinez. 2000. The end-of-day far red irradiation increases gibberellin $\mathrm{A}_{1}$ content in cowpea (Vigna sinensis) epicotyls by reducing its inactivation. Physiol. Plant. 108:426-434.

Mortensen, L.M. and E. Stromme. 1987. Effects of light quality on some greenhouse crops. Scientia Hort. 33:27-36.

Murakami, K., H. Cui, M. Kiyota, Y. Takemura, R. Oi, and I. Aiga. 1996.
Covering materials to control plant growth by modifying the spectral balance of daylight. Plasticulture 110:2-14.

Nishijima, T., M. Nonaka, M. Koshioka, H. Ikeda, M. Dozono, H. Yamazaki, and L.N. Mander. 1997. Effect of diurnal temperature fluctuation on endogenous gibberellins and stem elongation of Dendranthema grandiflorum Tzelev. Biosci. Biotechnol. Biochem. 61:1362-1366.

Noguchi, H. and T. Hashimoto. 1990. Phytochrome mediated synthesis of novel growth inhibitors, A-2a and b, and dwarfism in peas. Planta 181:256-262

Oi, R., N.Arai, Y. Matsuzaki, K. Seino, O. Kohgo, S. Ikado, M. Iwata, and K. Murakami. 1998. Photoselective plastics and their effects on plant growth. Proc. Natl. Agr. Plastics Congr. 27:35-40.

O'Neill, D.P., J.J. Ross, and J.B. Reid. 2000. Changes in gibberellin A levels and response during de-etiolation of pea seedlings. Plant Physiol. 124:805-812.

Rajapakse, N.C. and J.W. Kelly. 1991. Influence of $\mathrm{CuSO}_{4}$ spectral filters, daminozide, and exogenous gibberellic acid on growth of Dendranthema $\times$ grandiflorum (Ramat.) Kitamura 'Bright Golden Anne'. J.Plant Growth Regulat. 10:207-214.

Rajapakse, N.C. and J.W. Kelly. 1992. Regulation of chrysanthemum growth by spectral filters. J. Amer. Soc. Hort. Sci. 117:482-485.

Rajapakse, N.C., M.J. McMahon, and J.W. Kelly. 1993. End of day far red light reverses the height reduction of chrysanthemum induced by $\mathrm{CuSO}_{4}$ spectral filters. Scientia Hort. 53:249-259.

Rajapakse, N.C., R.E. Young, and R. Oi. 1998. Plant growth regulation by photoselective greenhouse covers. Proc. Natl. Agr. Plastics Congr. 27:23-29.

Reid, J.B. and J.J. Ross. 1988. Internode length in Pisum: A new gene, $l v$, conferring an enhanced response to gibberellin $\mathrm{A}_{1}$. Physiol. Plant. 72:595604.

Reid, J.B., J.J. Ross, and O. Hasan. 1991. Internode lengths in Pisum: Gene lkc. J. Plant Growth Regulat. 10:11-16.

Sager, J.C., W.O. Smith, J.C. Edwards, and K.L. Cyr. 1988. Photosynthetic efficiency and phytochrome photoequilibria determination using spectral data. Trans. Amer. Soc. Agr. Eng. 31:1882-1887.

Tatineni, A. R.T. Fernandez, and N.C. Rajapakse. 2000. Effectiveness of growth regulators under photoselective greenhouse covers with varying phytochrome photoequilibriums. J. Amer. Soc. Hort. Sci. 125:673-678.

Toyomasu, T., H. Yamane, I. Yamaguchi, N. Takahashi, and Y. Inoue. 1992. Control by light of hypocotyl elongation and levels of endogenous gibberellins in seedlings of Lactuca sativa L. Plant Cell Physiol. 33:695701.

van Haeringen, C.J., J.S. West,F.J. Davis, A. Gilbert, P. Hadley, S. Pearson, A.E. Wheldon, and R.G.C. Henbest. 1998. The development of solid spectral filters for the regulation of plant growth. Photochem. Photobiol. 64:407-413.

van Huizen, R., J.A. Ozga, D.M. Reinecke, B. Twitchin, and L.N. Mander. 1995. Seed and 4-chloroindole-3-acetic acid regulation of gibberellin metabolism in pea pericarp. Plant Physiol. 109:1213-1217.

Weller, J.L, J.J. Ross, and J.B. Reid. 1994. Gibberellins and phytochrome regulation of stem elongation in pea. Planta 192:489-496. 